\title{
Transdisciplinary insight of digital architecture
}

\author{
Ricardo Mendes Correia \\ ISCTE-IUL / ISTAR-IUL, Portugal \\ rfmcj@iscte-iul.pt
}

Filipe Brandão

ISCTE-IUL / ISTAR-IUL, Portugal

fjsbo@iscte-iul.pt

\author{
Alexandra Paio \\ ISCTE-IUL and Vitruvius FABLAB / ISTAR-IUL \\ Portugal \\ alexandra.paio@iscte.pt
}

\begin{abstract}
Considering the question of collaborative research in architecture with other arts and science, the research outlines a historic perspective of transdisciplinary digital architecture through the work of key personalities by establishing links between them. Researches on digital architecture history are generally grounded on methods with limited sets of primary sources and relevant data is overlooked. Following the increasing availability of digital data there are sources of information widely available on the internet, which have been previously ignored, and by using this new methodology they can be useful for scientific research, and specifically for this research. Data-driven and geospatial approaches can allow researchers to address multidimensional aspects. This paper presents the first preliminary results of an ongoing research.
\end{abstract}

Keywords: Digital; Transdisciplinary; Architecture; Bauhaus; Sketchpad

\section{Introduction}

"The digital is no longer a black box, a magic thing that's going to fulfill a vision of the future, rather it is a concrete thing with character and limits and influences. Today, it's time to start to write a history and theory of digital (...)"(Lynn, 2013, cover).

Architecture and design can be considered resilient by nature and had undergone through a complex change in the second half of the $20^{\text {th }}$ century. The ongoing research focuses on building a historic perspective of Transdisciplinary Digital Architecture, by establishing links between the work of key personalities, the institutions and cities where they worked, and their relevance to nowadays architecture. Digital Architecture is briefly defined as an assortment of digital architectures, comprising topological space, isomorphic surfaces, kinematics, genetic algorithms and parametric design (Kolarevic, 2000, 2001, 2004; Oxman, 2005, 2008; Mitchell, 1999). While transdisciplinary architecture can be succinctly described as an architecture of a hybrid nature redefined by other disciplines to target complex problems (Burry, 2012; Lawrence \& Després, 2004). Mark Burry, Carole Despres, Roderick Lawrence Isabelle Doucet and Nel Janssens have contributed to the idea of using transdisciplinarity in architectural research, teaching and practice (Burry, 2013; Després, 2012; Doucet \& Janssens, 2011; Lawrence \& Després, 2004).

Thus, if we look to contemporary architecture, it is a discipline that besides being digital it can also be considered transdisciplinary. Transdisciplinarity is a research strategy that crosses several disciplinary boundaries to create a holistic approach. Of all the mentioned authors and relatively recent approaches, none has considered the Transdisciplinary Digital Architecture in a historic perspective. Following this, the main purpose of this research is to contribute to that perspective with a new methodology. Thus, the present research established two inception points: (1) the transdisciplinary starts at Bauhaus in Weimar (1919); and, (2) the digital starts with Sketchpad, at MIT (1963) (Gropius, 1965; Moholy-Nagy, 1947; I. Sutherland, 1963). This suggests that it is important to establish the connections between the Bauhaus teaching methods, the evolution of computing in architecture and transdisciplinarity. By establishing those links, it can be possible to demonstrate what are the main contributions to the history and theory of digital architecture and to the topic of this paper.

Many researchers pointed that part of Bauhaus faculty went to the UK in the thirties, taking part in the British avant-garde movement. Those emigrated architects and artists took those ideas when they re-emigrated to the USA, when World War II started. This enabled the flourishing of those transdisciplinary ideas on universities on both sides of the Atlantic, and the present research intents to establish those links (Finch, 2005; Keller, 2005; Kentgens-Craig, 2001; Martin, Nicholson, \& Gabo, 1937; Picon, 2010; Rocha, 2004; Whitford, 1984).

The adopted methodology consists in the use of classical historical research methods assisted by computational methods. Data-driven and geospatial approaches associated with classification strategies to produce new knowledge by sorting and structuring data into an organized system. This manuscript presents only a brief overview on the topic of Transdisciplinary Digital Architecture. 


\section{Transdisciplinary}

Transdisciplinarity is a relatively young expression used for the first time less than fifty years ago, at Organization for Economic Co-operation and Development (OECD) congress. Many publications credited the term to Swiss psychologist Jean Piaget. However, considering the published proceedings of the OECD congress, the term was used by Jean Piaget, Erich Jantsch and Andre Lichnermicz (Jantsch, 1972; Julie Thompson Klein, 2013; Lichnerowicz, 1972; Nicolescu, 2003, 2006; Piaget, 1972). Nevertheless, it is important to state that Basarab Nicolescu, one of the most published transdisciplinary proponents, argues that the term was coined by Piaget a year earlier and that the Swiss asked the others to speak about the new concept. This view is in part confirmed by Jantsch in his paper confirming the early access to Piaget's paper to the congress (Jantsch, 1972; Lichnerowicz, 1972; Nicolescu, 2003, 2006; Piaget, 1972)

In architecture, transdisciplinary is a new way of teaching, researching and practicing. Architects like Mark Burry, Carole Despres, Roderick Lawrence Isabelle Doucet and Nel Janssens have contributed to the definition of transdisciplinarity. Doucet and Nel Janssens (2011) were the editors of one of the first books fully committed to transdisciplinary architecture: "Transdisciplinary Knowledge Production in Architecture and Urbanism" (Doucet \& Janssens, 2011) (Burry, 2013; Lawrence \& Després, 2004). In the foreword of this book, Julie Thompson Klein, perchance one of the most important scholars on transdisciplinary areas (Doucet \& Janssens, 2011), defines transdisciplinarity as a:

"New mode of inquiry, practice, and learning that places ethics, aesthetics, and creativity inside, not outside, of disciplinary and professional work." (Klein in Doucet and Janssens, 2011, p. vi)

"The boundary work of transdisciplinarity is decidedly plural. It is generative, formative, and interrogative, catalysing critique and transformations of our modes of inquiry, practice, and education." (Klein in Doucet and Janssens, 2011, p. vi)

\section{Transdisciplinarity approaches}

Based on the literature review is possible to define different visions of transdisciplinarity. These started in 1970 when Piaget and Lichnerowicz regarded transdisciplinarity as a conceptual tool, focused on internal dynamics of science. On the other hand, Jantsch, was perhaps more innovative because he had a vision that can be considered more organizational, looking to the general system of society and considering transdisciplinarity "the ultimate degree of coordination in the education" (Apostel, 1972; Jantsch, 1972; Klein, 2004b).

Those different starting visions progressed to two different transdisciplinary approaches. The first approach was developed and published in 1985 by Romanian physicist Basarab Nicolescu in his book Nous, la particule et le monde, where he introduces a methodology based on 3 axioms: ontology, logic of the included middle and epistemology. This methodology is commonly called the Nicolescuian approach. In 1994, Nicolescu, with philosopher Edgar Morin and others, was one of the organizers of the First World Congress of Transdisciplinarity where the Charter of Transdisciplinarity was adopted (Augsburg, 2014; Bernstein, 2015; Klein et al., 2012; Julie Thompson Klein, 2004a; McGregor, 2015; Nicolescu, 1985, 1996, 2006; Segalàs \& Tejedor, 2013).

But this Nicolescuian approach to transdisciplinarity was, perchance, more radical concerning the total abolition of frontiers between disciplines. A new approach was elaborated at the International Transdisciplinarity Conference in Zurich, in 2000 , usually called the Zurich approach, whose main figure is Julie Thompson Klein, an American scholar in the field of Humanities and Interdisciplinary Studies. This second and latest approach is more concerned with addressing complex societal problems such as those related to sustainability and joint problem solving (Augsburg, 2014; Bernstein, 2015; Klein et al., 2012; McGregor, 2015; Segalàs \& Tejedor, 2013).

"Transdisciplinarity is a new form of learning and problem solving involving cooperation among different parts of society and academia in order to meet complex challenges of society. Transdisciplinary research starts from tangible, real-world problems. Solutions are devised in collaboration with multiple stakeholders. A practice-oriented approach, transdisciplinarity is not confined to a closed circle of scientific experts, professional journals and academic departments where knowledge is produced." (Klein et al., 2001, p.7)

In fact, transdisciplinarity is a concept that has evolved since the seventies like computer aided design (CAD) had evolved since the sixties. It is also a fact that universities like MIT, where Jantsch was a visiting research associate, had CAD classes before 1970. It can be considered that digital architecture was on the path of transdisciplinarity even before the term was coined (Apostel, Berger, Briggs, \& Michaud, 1972; Jantsch, 1969; Rocha, 2004; Steenson, 2014)

In architecture, there are other important examples of researching and teaching with a transdisciplinary methodology. Roderick Lawrence and Carole Despres edited an issue of Futures scientific journal fully dedicated to transdisciplinarity and provided important contributions to the transdisciplinarity concept on the editorial. Despres, a Canadian Architect who besides the referred edition had an article in the Doucet and Janssens previously mentioned book, has more than twenty-five years of experience in Multidisciplinary and Transdisciplinary research related to housing, mainly in suburban areas. Other example is the New Zealander Mark Burry, best known for its decades of work in Antoni Gaudi's Sagrada Familia but who, like Despres, has years of teaching and researching experience with transdisciplinarity (Ahrentzen, Després, \& Schermer, 2012; Després, 2012; Doucet \& Janssens, 2011; Hensel, 2013; Lawrence \& Després, 2004; Menges \& Ahlquist, 2011; van Hensbergen, 2017). 


\section{Carole Despres and Mark Burry}

Despres career in transdisciplinarity can be understood in a biographic article called "Transdisciplinarity at Work in Housing Research". Despres writes about her professional experience of more than twenty years as researcher, first with Multidisciplinary Research, then with Interdisciplinary Research and at last with transdisciplinarity. For Despres, transdisciplinarity is a new methodology of looking at the relationship between knowledge, science and society and as way of attacking complexity in science (Ahrentzen et al., 2012; Després, 2012; Lawrence \& Després, 2004).

Mark Burry has another main theme of research besides Sagrada Familia that is transdisciplinary design education and practice (Burry, 2011, 2013; M. Hensel, Menges, \& Weinstock, 2006; M. U. Hensel, 2013). In the book Design innovation for the built environment: Research by design and the renovation of practice, Burry describes the work with transdisciplinarity: a "transdisciplinarian develops their own discipline through practice while enmeshed with others in shared design space, but they also redefine their discipline through project-based working association" (Burry, 2013, p.84)
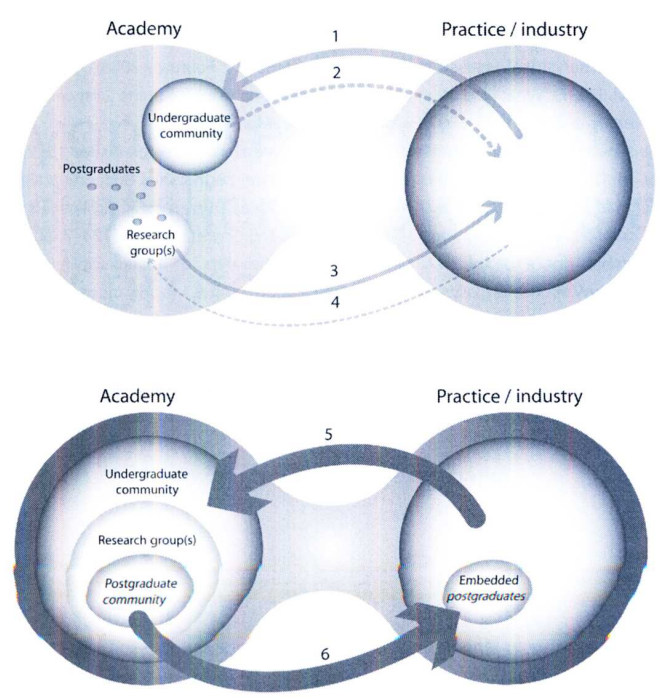

Figure 1: Facilitating trandisciplinarity: Academy and Practice. From: Burry (2013)

While at Royal Melbourne Institute of Technology, Burry was the founding Director of RMIT's Spatial Information Architecture Laboratory (SIAL) in 2001. SIAL experience can be described as a learning and research environment of fusion across a wide range of design disciplines. With Burry, RMIT evolved from SIAL to the creation of a university wide transdisciplinary Design Research Institute (DRI) established in 2008. Burry considers transdisciplinarity is an essential ingredient to amplify the scope of design research (Burry, 2013; Hensel, 2013).

Burry and Despres are using transdisciplinarity in teaching, research and practice in a digital architectural era. This research considers that before architecture went digital and
CAD could be fully used by architects, architecture had to go quantitative first.

\section{Transdisciplinary Digital Architecture}

Transdisciplinary Digital Architecture deals with digital means and with science. One possible reason is that the adoption of computation in architecture came as a consequence of the adoption of methods of other sciences, particularly mathematics, as Lionel March, one of the first architectural computer users suggests: "As soon as you did that you were involved in computing, because the mathematical models you developed for complex things could only really be worked out in particular instances by computing" (March in Bruton, 1997, p.316).

Christopher Alexander was one of the first architects to use mathematical models in architecture and urban design and he was using science, in architecture, while Ivan Sutherland was developing Sketchpad, the first interactive CAD. Alexander and his $\mathrm{PhD}$ dissertation advisor and coauthor Serge Chermayeff, considered that design quality could be improved by technology and science and in a certain way by what is termed, in present-day, as transdisciplinarity (Burry, 2013; Chermayeff \& Alexander, 1963; Després, 2012; Steenson, 2014; I. Sutherland, 1963).

"The designer must learn to approach technological changes by taking into account well-known scientific, social and technical data outside his field that may have an indirect influence upon his work " (Chermayeff and Alexander, 1963, p.108).

Alexander like March and Nicholas Negroponte were some of the few first architects to use computers in architecture, and all of them were in the Boston area in the first half of the sixties. They were among the limited number that had computers to make digital architecture and to use science with architecture (Chermayeff \& Alexander, 1963; Keller, 2006; March, 2000; Negroponte, 1966; Rocha, 2004; Steenson, 2014).

"So I was interested in at the same time in mathematical applications in the sciences seeing how all that was developing and then asking myself why aren't we using the power of mathematics to think in the arts, in architecture, in urban design" (March in Bruton, 1997, p.316).

"The architect becomes more knowledgeable of computer sciences; the computer, likewise, learns something about the architect and his idiosyncrasies" (Negroponte, 1966, p. 98) .

Alexander, March Negroponte and Mitchell, were students or researchers under the guidance of Chermayeff or Kepes from the group of emigrated architects and designers. In the UK, Alexander and March were also students at Cambridge with Martin, friend of Chermayeff, Kepes, Gropius and MoholyNagy (Alexander, 1964; Chermayeff \& Alexander, 1963; Picon, 2010; Rocha, 2004; Steenson, 2014). 
Nowadays digital architecture is, probably, the offspring of what Tafuri called, in 1968, "ex-machina architecture", referring to Alexander, and, at the same time, an important component of the research methodology (Alexander, 1964; Tafuri, 1980).

Literature review has allowed identifying relevant scientific works to the understanding of how digital technologies are changing not only architecture theory, but also teaching, researching and architectural practice. Those works are Architecture theory, 1960-1980: emergence of a computational perspective (Rocha, 2004), Builders of the Vision ((Cardoso, 2012), Builders of the Vision: Software and the Imagination of Design (Cardoso, 2015), Architectures of Information: Christopher Alexander, Cedric Price, and Nicholas Negroponte \& MIT's Architecture Machine Group (Steenson, 2014) e $3 D$ Modeling and the Seduction of the Real (Perry, 2014) and Digital culture in architecture (Picon, 2010). In the reviewed literature, even if their authors are not relating digital architecture history with Transdisciplinarity, the architecture science association is referred. The clearest approaches to transdisciplinary architecture are given by Rocha's mention to architecture quantitative revolution or Cardoso's re-definition of the disciplinary boundaries when focusing BIM. Furthermore, Steenson suggests transdisciplinarity to classify Christopher Alexander PhD dissertation, The Synthesis of Form: Some Notes on a Theory and Picon considers nowadays architecture is in part a consequence of a "Second Industrial Revolution", the information and communication revolution (Cardoso, 2012; Perry, 2014; Picon, 2010; Rocha, 2004; Steenson, 2014).

This research considers the referred literature essential to understand digital architecture history and to understand some of the links between key personalities but none of those authors provides a Transdisciplinary perspective of Digital Architecture history like this research aims to do. Of all the above-mentioned authors, in Digital Architecture history field or in the Transdisciplinarity field, no other work is known in Transdisciplinary Digital Architecture like the present research.

Perhaps the only author that blended transdisciplinarity and digital in his main research themes is Mark Burry, but not on a historic perspective. Burry as a "transdisciplinarian" considers that "Digital design is now fully assimilated into design practice, and we are moving rapidly from an era of being aspiring expert users to one of being adept digital toolmakers". As above mentioned, we have not found in the referred literature, any published work based mainly on a historic perspective of Transdisciplinary Digital Architecture (Burry, 2011; Burry \& Murray, 1997; M. U. Hensel, 2013; Kolarevic, 2000; Oxman, 2008; Peters \& Peters, 2013).

Another important issue is that some of the most significant authors related to the definition of digital architecture did not provide approaches to Transdisciplinary Digital Architecture. It is not known what important researchers in digital architecture, like Kolarevic $(2000,2001,2004)$, Oxman $(2005,2008)$ or Mitchell (1999), thought about transdisciplinarity in digital architecture teaching and research.
In the United Kingdom, in the interwar period, there was an avant-garde scene that mixed British and refugee architects, artists, writers and scientists best known by being the collective that authored the 1937 book Circle. Rocha's PhD dissertation, Architecture theory, 1960-1980: emergence of a computational perspective, demonstrated the relation between science and architecture in that British thirties scene and the connection to the computer use of the in architecture in the sixties. On the Circle group, there was Leslie Martin, March, Alexander's Cambridge teacher, Chermayeff, Gyorgy Kepes, his co-worker Lazlo Moholy-Nagy and Walter Gropius, both previously Bauhaus' school staff (Martin et al., 1937; Rocha, 2004).

\section{Methodology}

This research is about innovation in architecture and adopted a methodology that is focused on using innovative digital tools that helped to shape the 21st century architecture. Following the increasing availability of digital data and media sources, it is possible to mix together text, audio, picture, video as well as alphanumerical databases and geographic information system (GIS). These massive amounts of machine-readable information are helping us to trace links in a historical perspective of Transdisciplinary Digital Architecture.

The research question lies in understanding what were the main contributions to this Transdisciplinary Digital Architecture. A practice that uses a new approach with digital technologies and other disciplines. As a preliminary point, this research considers a corpus of 13 key figures:

Walter Gropius
László Moholy-Nagy
Serge Chermayeff
György Kepes
Leslie Martin
Steven Coons
Herbert Simon
Lionel March
Christopher Alexander
Ivan Sutherland
Nicholas Negroponte
William Mitchell
Charles Eastman

All the key figures are from academia, not all architects but all of them teachers, researchers, and advisors of new generations of architects. All of them were innovative, in teaching methodologies they used and have gone a step further, either by founding schools and university centers, research laboratories, publishing scientific books or even creating computerized manifolds, software and computer peripherals. 


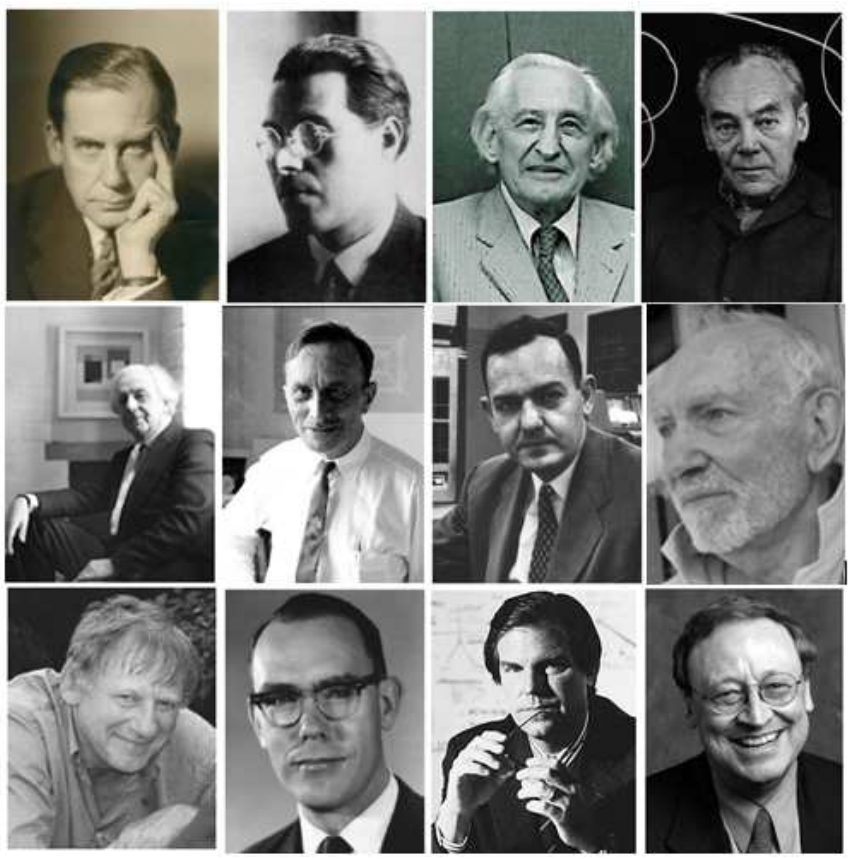

Figure 2: Transdisciplinary Digital Architecture Key Figures

The use of other collected data like, for instance, publications metadata, gives us the possibility to use secondary sources that could not be employed directly on a research. That data can be collected in databases to be applied in a GIS, creating a geospatial temporal database to establish the links between key figures and to illustrate geospatially and even temporally the relationships and interactions between people, places, and institutions. But to achieve a good visualization of the interactions, data collection and data storing accuracy are essential. The database must have structured fields to expand the possibilities of executing relational or spatial queries that can be helpful to illustrate connections.

\section{Preliminary findings}

Preliminary findings show a link between a first generation, the 1920's Bauhaus teachers Gropius and Moholy-Nagy, friends and mentors of a second generation constituted by Chermayeff, Kepes and Martin. This second generation of science and architecture academia were teachers and advisors of March, Alexander, Negroponte and Mitchell (Rocha, 2004; Steenson, 2014).

For instance, Negroponte had three dissertation advisors, one was Kevin Lynch, the other was Kepes and the third was Coons, one of the MIT's CAD project directors, where Sutherland's Sketchpad was being developed. Keeps had worked for years with Moholy-Nagy and was a close friend of Gropius. Lynch had worked with Kepes on The Image Of The City and with March and Alexander at the MIT and the Harvard Joint Center for Urban Studies (Cardoso, 2012; Coons, 1967; Keller, 2006; Lynch, 1960; March, 2000; Negroponte, 1966; Perry, 2014; Steenson, 2014; I. Sutherland, 1963).
After concluding his PhD degree, Alexander became Professor at Berkeley and Eastman was his student. After graduating, Eastman went to Pittsburgh's Carnegie Mellon University (CMU) to have Herbert Simon as his PhD dissertation advisor. And if Simon turned design in one of The Sciences Of The Artificial in late sixties, Eastman still is, in 2017, a crucial figure and best known for being one of the first and most fluent promoters of BIM (Cardoso, 2012; Rocha, 2004; Simon, n.d.; Steenson, 2014).

Both Alexander's research work for A Pattern Language, started in the late sixties, and March's pioneer work with urban forms at Cambridge LUBFS may have been ground-breaking and influential to the development of Transdisciplinary Digital Architecture, including the use of tools like GIS, shape grammars and space syntax. , The work of non-architects like Coons, a kind of a father figure to the NURBS and b-splines, or Sutherland, who developed both Sketchpad and the first known virtual reality hardware, was also crucial for Transdisciplinary Digital Architecture (Alexander, Ishikawa, \& Silverstein, 1977; Bruton, 1997; Keller, 2005; Perry, 2014; Riesenfeld, 1973; Rocha, 2004; Steenson, 2014; I. Sutherland, 1963; I. E. Sutherland, 1968; Versprille, 1975).

It is expected, with this ongoing research, to extend the application of computational methods to historical research by tracing the evolution of the research topic.

\section{Discussion}

The ongoing research goal is to go a bit further, trying to identify a clear link between a "first age" transdisciplinarity with the Bauhaus teaching methods, the early use of computers in architecture and subsequent changes in architectural research, teaching and practice methods. Therefore, the research focuses on a different approach to historical research in architecture. While it studies quantitative methods in architectures, it uses those methods in the research. We foresee some difficulties in data collection and, in a less extent, in structuring database fields and in illustrating the relational data. Nevertheless, even if the research is in an early stage we could organize data in a database and use it to validate some information taken from literature review.

We have retrieved data from curricula and obituaries and organized it in a spatial and temporal database and, with the use of GIS software, confirmed that from 1960 to 1962, eight of the key personalities were working in the Boston area. In fact, the literature review also allowed to conclude that in the first years of 1960's Gropius, Chermayeff, Kepes, Coons, Sutherland, March; Alexander and Negroponte worked in Cambridge, Massachusetts. Eight out of the 12 key personalities that were alive by then, were at the same coordinate, at the same time (Anderson, 2010; Chermayeff \& Alexander, 1963; March, 2000; Pearlman, 2007; Rocha, 2004; Steenson, 2014; I. Sutherland, 1963).

It is not possible, at this early stage, fully assure that this method can provide a powerful analytical tool to graphically trace all the interactions but, with the development of the 
research, we will be able to fully confirm that this method provides a distinct quantitative analytical method to scrutinize links between key personalities in a historical perspective. Additionally, we hope to validate the use of computational methods of mapping, analysis and visualization in architectural historical research.

\section{References}

Ahrentzen, S., Després, C., \& Schermer, B. (2012). Building Bridges, Blurring Boundaries: The Milwaukee School in EnvironmentBehavior Studies. University of Wisconsin-Milwaukee and Villes Régions Monde.

Alexander, C. (1964). Notes on the Synthesis of Form (Harvard Paperbacks).

Alexander, C., Ishikawa, S., \& Silverstein, M. (1977). A Pattern Language. Oxford University Press.

Anderson, S. (2010). Considering Peter Behrens Interviews with Ludwig Mies van der Rohe (Chicago, 1961) and Walter Gropius (Cambridge, MA, 1964).

Apostel, L. (1972). Introduction. Interdisciplinary: Problems of Teaching and Research in Universities. Paris: OECD, 23-82.

Apostel, L., Berger, G., Briggs, A., \& Michaud, G. (1972). Interdisciplinarity Problems of Teaching and Research in Universities.

Augsburg, T. (2014). Becoming Transdisciplinary: The Emergence of the Transdisciplinary Individual, 70, 3-4. https://doi.org/10.1080/02604027.2014.934639

Bernstein, J. H. (2015). Transdisciplinarity: A review of its origins, development, and current issues. Journal of Research Practice, 11(1), 1 .

Bruton, D. (1997). A contingent sense of grammar. University of Adelaide.

Burry, M. (2011). Scripting cultures: Architectural design and programming. John Wiley \& Sons.

Burry, M. (2013). Towards meeting the challenges of facilitating transdisciplinarity in design education, research and practice. In M. U. Hensel (Ed.), Design Innovation for the Built Environment: Research by Design and the Renovation of Practice. Routledge.

Burry, M., \& Murray, Z. (1997). Architectural design based on parametric variation and associative geometry.

Cardoso, D. (2012). Builders of the Vision. Massachusetts Institute of Technology

Cardoso, D. (2015). Builders of the Vision: Software and the Imagination of Design. Routledge.

Chermayeff, S., \& Alexander, C. (1963). Community and privacy: Toward a new architecture of humanism. Doubleday.

Coons, S. A. (1967). Surfaces for Computer-Aided Design of Space Forms.

Després, C. (2012). Transdisciplinarity at Work in Housing Research. In Building Bridges, Blurring Boundaries (p. 239).

Doucet, I., \& Janssens, N. (2011). Transdisciplinary knowledge production in architecture and urbanism: Towards Hybrid Modes of Inquiry (Vol. 11). Springer Science \& Business Media.

Finch, E. (2005). Languages of Vision: Gyorgy Kepes and the New Landscape of Art and Science. Ann Arbor, MI: UMI Dissertation Publication. https://doi.org/10.1177/001088048102200214

Gropius, W. (1965). The new architecture and the Bauhaus (Vol. 21). Mit Press.

Hensel, M., Menges, A., \& Weinstock, M. (2006). Techniques and technologies in morphogenetic design. Wiley-Academy London.

Hensel, M. U. (2013). Design Innovation for the Built Environment: Research by Design and the Renovation of Practice. (M. U. Hensel, Ed.) (Design Inn). Taylor \& Francis.

Jantsch, E. (1969). Integrative Planning for the" Joint Systems" of Society and Technology-the Emerging Role of the University. Ekistics, 371-380.

Jantsch, E. (1972). Towards interdisciplinarity and transdisciplinarity in education and innovation. Interdisciplinarity: Problems of Teaching and Research in Universities, 97-121.

Keller, S. B. (2005). Systems Aesthetics: Architectural Theory at the University of Cambridge, 1960-75: a Thesis. UMI Dissertation Services.

Keller, S. B. (2006). Fenland Tech: Architectural Science in Postwar Cambridge. Grey Room, 23, 40-65. https://doi.org/10.1162/grey.2006.1.23.40

Kentgens-Craig, M. (2001). The Bauhaus and America: first contacts, 1919-1936. Mit Press.

Klein, J. T. (2004a). Prospects for transdisciplinarity. Futures, 36, 515526. https://doi.org/10.1016/j.futures.2003.10.007

Klein, J. T. (2004b). Unity Of Knowledge And Transdisciplinarity: Contexts Of Definition, Theory And The New Discourse Of Problem Solving. In Unity of Knowledge (in Transdisciplinary Research for Sustainability) - Volume I: (pp. 35-39).

Klein, J. T. (2013). The Transdisciplinary Moment(um), 9(2). Retrieved from https://www.integralreview.org/issues/vol_9_no_2_klein_the_transdiciplinary_mo ment(um).pdf

Klein, J. T., Grossenbacher-Mansuy, W., Häberli, R., Bill, A., Scholz, R. W., \& Welti, M. (2001). Transdisciplinarity: Joint Problem Solving Among Science, Technology, and Society: An Effective Way for Managing Complexity. SPRINGER VERLAG NY.

Klein, J. T., Grossenbacher-Mansuy, W., Häberli, R., Bill, A., Scholz, R. W., \& Welti, M. (2012). Transdisciplinarity: joint problem solving among science, technology, and society: an effective way for managing complexity. (J. T. Klein, W. GrossenbacherMansuy, R. Häberli, A. Bill, R. W. Scholz, \& M. Welti, Eds.). Birkhäuser.

Kolarevic, B. (2000). Digital architectures. In Proceedings of the ACADIA 2000 Conference, ACADIA.

Kolarevic, B. (2001). Designing and manufacturing architecture in the digital age. Architectural Information Management, 20011172001123.

Kolarevic, B. (2004). Architecture in the digital age: design and manufacturing. Taylor \& Francis.

Lawrence, R. J., \& Després, C. Futures of transdisciplinarity, 36Futures 397-405 (2004). Pergamon. https://doi.org/10.1016/j.futures.2003.10.005

Lichnerowicz, A. (1972). Mathematic and Transdisciplinarity. Interdisciplinarity: Problems of Teaching and Research in Universities, 97-121.

Lynch, K. (1960). The image of the city (Vol. 11).

Lynn, G. (2013). Archaeology of the Digital. Sternberg Press.

March, L. (2000). Setting out the possibilities: Leslie Martin and the advancement of architectural knowledge. Architectural Research Quarterly, 4(4).

Martin, J. L., Nicholson, B., \& Gabo, N. (1937). Circle; International Survey of Constructive Art. Praeger Publishers.

McGregor, S. L. T. (2015). The Nicolescuian and Zurich approaches to transdisciplinarity. Integral Leadership Review, 15(2).

Menges, A., \& Ahlquist, S. (2011). Computational Design Thinking: Computation Design Thinking. Wiley. Retrieved from https://books.google.pt/books?id=lb4yEJErR5EC

Mitchell, W. J. (1995). City of bits. Space, Place, and the Info. Cambridge Univ Press.

Moholy-Nagy, L. (1947). The new vision and Abstract of an artist. Wittenborn, Schultz New York.

Negroponte, N. (1966). The Computer Simulation Of Perception During Motion In The Urban Environment. Retrieved from https://dspace.mit.edu/bitstream/handle/1721.1/13288/250607 34-MIT.pdf?sequence $=2$

Nicolescu, B. (1985). Nous, la particule et le monde. Le Mail.

Nicolescu, B. (1996). La transdisciplinarité, manifeste. (Jean, -, \& P. Bertrand, Eds.) (Collection). Monaco: Le Rocher.

Nicolescu, B. (2003). Definition of transdisciplinarity. In RETHINKING INTERDISCIPLINARITY (pp. 3-5). C.N.R.S. project Society of Information.

Nicolescu, B. (2006). Transdisciplinarity: past, present and future. Moving Worldviews: Reshaping Sciences, Policies and Practices for Endogenous Sustainable Development, 
ETC/COMPAS, Leusden, 142-166.

Oxman, R. (2005). The conceptual content of digital architecture. A content analysis in design. Arquiteturarevista (Brasil) Num.1 Vol.1.

Oxman, R. (2008). Digital architecture as a challenge for design pedagogy: theory, knowledge, models and medium. Design Studies, https://doi.org/10.1016/j.destud.2007.12.003

Pearlman, J. E. (2007). Inventing American Modernism: Joseph Hudnut, Walter Gropius, and the Bauhaus Legacy at Harvard. University of Virginia Press.

Perry, R. A. (2014). Rigging the world: 3D modeling and the seduction of the real. Massachusetts Institute of Technology.

Peters, T., \& Peters, B. (2013). Inside Smartgeometry: expanding the architectural possibilities of computational design. John Wiley \& Sons.

Piaget, J. (1972). L'epistemologie des relations interdisciplinaires. Interdisciplinarity: Problems of Teaching and Research in Universities, 127-139. Retrieved from http://www.fondationjeanpiaget.ch/fjp/site/textes/VE/jp72_epist relat_interdis.pdf

Picon, A. (2010). Digital culture in architecture. Basel, Switzeland: Birkhauser.

Riesenfeld, R. (1973). Applications of B-spline approximation to geometric problems of computer-aided design. Syracuse University.
Rocha, A. J. J. (2004). Architecture theory, 1960-1980: emergence of a computational perspective. Massachusetts Institute of Technology.

Segalàs, J., \& Tejedor, G. (2013). Transdiciplinarity. A must for sustainable education. In Keynote address at the 41st SEFI Conference, Leuven, Belgium.

Simon, H. A. (n.d.). The Sciences of the Artificial.

Steenson, M. W. (2014). Architectures of Information: Christopher Alexander, Cedric Price, and Nicholas Negroponte \& MIT's Architecture Machine Group.

Sutherland, I. (1963). SKETCHPAD-a man-machine graphical interface. PhD thesis, MIT.

Sutherland, I. E. (1968). A head-mounted three dimensional display. In Proceedings of the December 9-11, 1968, fall joint computer conference, part I (pp. 757-764).

Tafuri, M. (1980). Theories and history of architecture. (H. \& Row, Ed.) (Icon Editi).

van Hensbergen, G. (2017). The Sagrada Familia: Gaudi's Heaven on Earth. Bloomsbury Publishing. Retrieved from https://books.google.pt/books?id=1xqLDQAAQBAJ

Versprille, K. (1975). Computer-Aided Design Applications of the Rational B-Spline Approximation Form. Electrical Engineering and Computer Science - Dissertations. Syracuse University.

Whitford, F. (1984). Bauhaus. Thames and Hudson London. 